\title{
Revision of food-based dietary guidelines for Ireland, Phase 1: evaluation of Ireland's food guide
}

\author{
Mary AT Flynn*, Clare M O’Brien, Gemma Faulkner, Cliona A Flynn, Magda Gajownik \\ and Sarah J Burke \\ Public Health Nutrition, Food Safety Authority of Ireland (FSAI), Abbey Court, Lower Abbey Street, Dublin 1, \\ Republic of Ireland
}

Submitted 30 November 2010: Accepted 4 July 2011: First published online 14 September 2011

\begin{abstract}
Objective: To evaluate Ireland's food-based dietary guidelines and highlight priorities for revision.

Design: Evaluation with stakeholder input. Energy and nutrient intake goals most appropriate for Ireland were determined. Advice from Ireland's food guide was translated into $4 \mathrm{~d}$ food intake patterns representing age and gender groups from 5 to $51+$ years. Nutritional content of the food patterns was compared with identified goals and appropriateness of food advice was noted. Feedback from stakeholders was obtained on portion size of foods within the Bread, Cereal and Potato group and of portion descriptors for meat and cereal foods.

Setting: Government agency/community.

Subjects: General population aged $5+$ years, dietitians/nutritionists $(n 44)$ and 1011 consumers.

Results: Goals were identified for energy, macronutrients, fibre, Fe, Ca and vitamin D. Goals not achieved by the food patterns included energy, total fat, saturated fat, fibre and vitamin D. Energy content of food portions within the Bread, Cereal and Potato group varied widely, yet advice indicated they were equivalent. Dietitians/nutritionists agreed with the majority of consumers surveyed $(74 \%, n 745)$ that larger portion sizes within the Bread, Cereal and Potato group were more meaningful. 'Palm of hand' as a descriptor for meat portions and a '200 $\mathrm{ml}$ disposable cup' for quantifying cereal foods were preferred.

Conclusions: Revision of the guidelines requires specific guidance on energy and vitamin $\mathrm{D}$ intakes, and comprehensive advice on how to reduce fat and saturated fat and increase fibre intakes. Advice should use portion descriptors favoured by consumers and enlarged portion sizes for breads, cereals and potatoes that are equivalent in terms of energy.
\end{abstract}

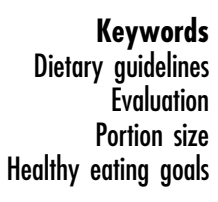

Dietary guidelines were originally developed to enable people select a balanced diet to meet their basic nutrient requirements. However, the role of optimal nutrient intake in the prevention of chronic diseases such as CVD, cancer, diabetes and obesity has become increasingly established $^{(1)}$. Consequently, dietary guidelines need to be assessed in terms of how well the advocated food patterns meet well-established nutrient goals for chronic disease prevention.

In 1992, the US Department of Agriculture published its Food Pyramid $^{(2)}$, which provided food guidance to meet targets for adequate nutrient intakes ${ }^{(3)}$. In 1993, the Department of Health and Children adopted the US food pyramid as Ireland's food guide with some amendments to include foods commonly eaten in Ireland. This has been used in nutrition health promotion ever since ${ }^{(4)}$.
Over the last three decades, there has been a global exponential rise in obesity ${ }^{(5-7)}$. In Ireland between 1990 and 1999 , obesity increased from $8 \%$ to $20 \%$ in men and from $13 \%$ to $16 \%$ in women ${ }^{(8)}$. By 1999 , an additional $46 \%$ of men and $33 \%$ of women were overweight ${ }^{(8)}$. Almost one in four boys and over one in four girls aged between 4 and 16 years in Ireland are either overweight or obese ${ }^{(9)}$. Another national study found that there has been a two- to fourfold increase in the prevalence of obesity among 8-12-year-olds between 1990 and $2005^{(10)}$. Due to rising obesity, the USA and Canada have revised their national food guides to include guidance on energy $^{(11,12)}$ and optimal nutrient intakes for chronic disease prevention. In 2010, the US Dietary Guidelines Advisory Committee further updated its guidelines to incorporate measures needed at environmental level to 
enable the population to achieve dietary and physical activity goals for obesity prevention ${ }^{(13)}$.

The Irish National Task Force on Obesity $(2005)^{(14)}$ and the Irish Heart Foundation (2007) ${ }^{(15)}$ have outlined the need for dietary strategies which help prevent obesity, CVD and other related chronic diseases. Reduction of total fat, saturated fats and trans fats and increased fibre intakes still remain priority population goals ${ }^{(15)}$. The latest dietary surveys in Ireland have found that fat intakes are excessive, with one-third of adults reaching the total fat goal of $\leq 35 \%$ energy $^{(16)}$. Approximately two-thirds of Irish adults do not reach the German goal of $30 \mathrm{~g}$ fibre/d and the Nordic goal of $3 \mathrm{~g} / \mathrm{MJ}$ per d (25 to $35 \mathrm{~g}$ fibre/d) ${ }^{(17)}$. The Irish Heart Foundation recently recommended an adult goal of $25 \mathrm{~g}$ fibre $/ \mathrm{d}^{(15)}$. The mean daily fibre intake in Ireland is $20 \mathrm{~g}$ for men and $17 \mathrm{~g}$ for women ${ }^{(17)}$.

There are three micronutrients of concern in Ireland $\mathrm{Fe}, \mathrm{Ca}$ and vitamin D. Fe is essential for the formation of $\mathrm{Hb}$, adequate growth and cognitive function. National surveys have found that the majority ( $72 \%$ ) of adolescent girls aged $13-17$ years and up to $50 \%$ of women aged $18-50$ years have inadequate $\mathrm{Fe}$ intakes ${ }^{(18,19)}$. In a study of 201 Dublin schoolgirls, it was found that $42 \%$ had low ferritin levels $(<15 \mu \mathrm{g} / \mathrm{l})$ and $3 \%$ were anaemic $(\mathrm{Hb}<$ $120 \mathrm{~g} / \mathrm{l})^{(20)}$. Similarly, adequate $\mathrm{Ca}$ intakes are necessary to ensure optimal bone metabolism. In adolescents and young adults, the achievement of peak bone mass is important for prevention of osteoporosis. Surveys in Ireland have found that $23 \%$ of women and $11 \%$ of men aged $18-50$ years and $42 \%$ of girls and $23 \%$ of boys aged $13-17$ years have inadequate $\mathrm{Ca}$ intakes ${ }^{(18,19)}$.

Vitamin D has an essential role in the prevention of rickets, osteomalacia and osteoporosis. The importance of vitamin $\mathrm{D}$ in the prevention of autoimmune diseases ${ }^{(21)}$, some cancers ${ }^{(22,23)}$, diabetes ${ }^{(23,24)}$ and $\mathrm{CVD}^{(23,25)}$ is also increasingly being established. Vitamin D is synthesized in the skin by the action of UVB rays in sunlight. However these UVB rays are severely compromised by geographical location (i.e. northerly latitude) and the winter season (September to March) ${ }^{(26,27)}$, factors which are relevant to Ireland. Vitamin D is found in few foods, such as oily fish, fortified margarines, breakfast cereals and milks. Therefore dietary intakes of vitamin D have been found to be low in most age groups in Ireland ${ }^{(28-30)}$, with adult men and women aged 18-64 years having mean intakes of $3.7 \mu \mathrm{g} / \mathrm{d}^{(30)}$.

In light of the obesity rates and their associated morbidities, an evaluation of Ireland's food pyramid (1993-2010) was undertaken. Three approaches were used to assess how well the food guidance delivered optimal intakes of energy, macronutrients, fibre, Fe, Ca and vitamin $\mathrm{D}$ and to identify those areas that need revision. First, food patterns for individuals, representing different age and gender groups, were developed from the food pyramid advice and evaluated in terms of identified nutritional intake goals. The findings were then presented to dietitians and nutritionists who provided input on options for revision. Finally, consumers were surveyed to assess their preferences for average portion sizes of starchy foods and for portion size descriptors.

\section{Methods}

Four age groups were considered for males and females to represent variation in nutrient requirements as follows: 5-13 years, $14-18$ years, $19-50$ years and $51+$ years. Goals for energy requirements were set using the approach outlined by the Institute of Medicine (IOM) ${ }^{(31)}$. Energy requirements were determined using equations that used reference heights (median heights) and weights that approximated 'ideal' body weights based on low risk of chronic disease for adults (BMI of $22.5 \mathrm{~kg} / \mathrm{m}^{2}$ for men and $21.5 \mathrm{~kg} / \mathrm{m}^{2}$ for women $\left.{ }^{(31)}\right)$. In addition to energy goals for moderate activity, goals for sedentary activity levels were included for the three older age and gender groups (see Table 1). 'Moderately active' is defined as a lifestyle that includes physical activity equivalent to walking 1.5 to 3 miles/d at $3-4$ miles $/ \mathrm{h}$ in addition to the activities of independent living ${ }^{(31)}$. 'Sedentary' is defined as a lifestyle that includes only physical activity of independent living ${ }^{(31)}$.

Well-established recommended intakes for total fat, saturated fat, protein, carbohydrate and fibre ${ }^{(15,31)}$ were used to set the macronutrient goals for adults and children aged 5-18 years except for dietary fibre where 'age $+5 \mathrm{~g}$ ' recommended by the American Health Foundation ${ }^{(32)}$ was used. For adults, the Irish Heart Foundation goal of $25 \mathrm{~g}$ fibre/d was adopted ${ }^{(15)}$. Goals for Fe (Estimated Average Requirements) were based on the Nordic Nutrition Recommendations ${ }^{(33)}$, and goals for Ca and vitamin D were based on Adequate Intakes (AI) recommended by the $\mathrm{IOM}^{(34)}$.

\section{Nutritional quality of advised food intake patterns}

Using the food pyramid advice, $4 \mathrm{~d}$ food intake patterns were developed for eleven hypothetical males and females representing the four age groups. Daily food intake patterns were derived according to the suggested numbers of servings from each food group (Bread, Cereal and Potato group, $6+$ servings; Fruit and Vegetables group, 5 servings; Milk, Cheese and Yoghurt group, 3 to 5 servings; Meat and Alternatives group, 2 servings). Overall, the advice was interpreted conservatively by registered dietitians using best food choices. For instance, it is advised that foods such as cakes, confectionery and savoury snacks be consumed in moderation. Accordingly, only small amounts of these foods were included (e.g. $1 \times 28 \mathrm{~g}$ packet of crisps in $4 \mathrm{~d}$ ). Cheese, a food high in both total fat and saturated fat, was positioned in two food groups and thereby could have been used twice in one day as a portion from the each of the two food groups. However, in this evaluation cheese was used 
once and counted as a portion from both food groups simultaneously.

Note was taken of any areas where guidance on food choice was ambiguous. Appropriateness of food advice was judged in terms of: specificity of portion size descriptions; typical eating patterns in Ireland; placement of foods in food groups; and clarity in terms of qualitative dietary advice.

Where portion size descriptions were ambiguous, portions sizes were assigned using the weights for 'medium' portions from the UK Food Standards Agency's food portion sizes handbook where possible ${ }^{(35)}$. For example, the descriptor 'a bowl of cereal' was translated into the weights assigned for a 'medium bowl' of different types of breakfast cereal. Alternatively, some cooked foods (e.g. pasta component of an individual portion of shop-bought lasagne) were weighed using electronic scales. The $4 \mathrm{~d}$ food intake patterns were analysed using NetWisp software version 3.0 (2006; Tinuviel Software, Anglesey, UK), based on McCance and Widdowson's The Composition of Foods, 6th edition ${ }^{(36)}$, to establish average daily energy and nutrient intakes. These average daily nutrient outputs were compared with the chosen goals for energy and nutrients (see Table 1).

\section{Consultation witb dietitians and nutritionists}

Forty-four dietitians/nutritionists participated in a Workshop Consultation Day where they were presented with the results of the evaluation of the food guide and requested to provide input on options for revision. Led by an independent facilitator, feedback was specifically requested on: (i) whether portion sizes within the Bread, Cereal and Potato group should be enlarged; (ii) which household descriptors are most appropriate for portions of meat, cereals and pasta; (iii) whether pulses should be allocated to two food groups (Meat and Alternatives group and Fruit and Vegetables group); (iv) whether cheese should be restricted to one food group (Dairy group); and (v) finally whether fat spreads and oils should be separated into a new food group. In addition, the acceptability of advice that includes 'sparing use' of sugar and preserves to increase the palatability of low-fat, high-fibre foods (wholemeal breads, cereals and stewed fruit) was considered.

Two food displays were developed as a visual aid to obtain feedback on portion size within the Bread, Cereal and Potato group. One display contained smaller portion sizes, which were based on the guidance in the food pyramid (1993-2010) but re-adjusted to ensure the range of energy provided was as narrow as possible. The second display contained larger portions of the same foods modelled on Australian portion sizes ${ }^{(37)}$. The displays demonstrated that the smaller portions $v$. larger portions included half a roll $v$. a whole roll, or half a pitta bread $v$. a whole pitta bread. The energy provided by the foods in the smaller display ranged between 293 and $523 \mathrm{~kJ}$ (70 and $125 \mathrm{kcal})$, and for the larger display ranged between 460 and $912 \mathrm{~kJ}$ (110 and $218 \mathrm{kcal}$ ).

\section{Consumer survey on portion size of starchy foods and portion size descriptors}

To assess the acceptability of portion sizes of foods from the Bread, Cereal and Potato group among consumers, a standardized questionnaire was piloted, designed and administered to shoppers at two large Dublin supermarkets (in an advantaged and a disadvantaged socio-economic area). A sample of 1011 respondents was surveyed, which just exceeded the target of 1000 consumers set to represent Dublin city's population (about 500000 inhabitants). The same food displays described above were used as a visual aid to help respondents answer the questionnaire. Consumers were asked which set of portion sizes 'make the most sense as average portions?' In addition, the same sample of consumers was asked whether they preferred 'palm of hand' or 'deck of cards' as a main meal descriptor for meat, chicken or fish. During the survey, following feedback from consumers about the difficulty in estimating portion sizes of foods such as cereals, rice and pasta, an additional question was introduced to the remaining 485 consumers. They were asked to indicate their preference for either a $200 \mathrm{ml}$ plastic disposable 'cup' or 'dessertspoons' as a portion size descriptor for cereals, rice and pasta. The data collected were analysed using the SPSS statistical software package version $14 \cdot 0$ (2005; SPSS Inc., Chicago, IL, USA) to compare preferences of consumers according to supermarket location, age and gender using the $\chi^{2}$ test.

\section{Results}

The nutrient goals used for the evaluation of the food pyramid (1993-2010) are outlined in Table 1. Figure 1 provides an overview of the average daily energy and nutrient intakes provided by $4 \mathrm{~d}$ food patterns for healthy eating derived from this food guide, in relation to the recommended daily intakes of energy and nutrients. Given in part (a) of Table 2 are details on the proportions of these average daily energy and nutrient intakes, generated for eleven individuals, which met the goals for healthy eating; while part (b) describes areas identified where food advice required revision.

Feedback from the dietitians and nutritionists (see Table 3) resulted in unanimous support for the use of larger portion sizes within the Bread, Cereal and Potato group, and for the separation of fat spreads and oils from 'other' foods. It was agreed that suitability of descriptors for foods such as meat, in addition to use of other household measures (cups and spoons), should be examined with consumers.

Table 4 outlines the shoppers' responses to which size portions of foods from the Bread, Cereal and Potato group were the best fit with their concept of 'average' portions and their preferences for portion size descriptors of other foods. Almost $75 \%$ of shoppers reported that the larger portions were 'the best fit with their idea of average' 
Table 1 Macronutrient and micronutrient goals used for the evaluation and revision of food-based guidelines for age and gender groups representative of Ireland's population aged 5 years and older

\begin{tabular}{|c|c|c|c|c|c|c|c|c|}
\hline \multirow[b]{3}{*}{ Nutrient } & \multicolumn{8}{|c|}{ Age and gender groups } \\
\hline & \multicolumn{2}{|c|}{$5-13$ years } & \multicolumn{2}{|c|}{$14-18$ years } & \multicolumn{2}{|c|}{$19-50$ years } & \multicolumn{2}{|c|}{$51+$ years } \\
\hline & Males & Females & Males & Females & Males & Females & Males & Females \\
\hline \multicolumn{9}{|l|}{ Energy* } \\
\hline \multicolumn{9}{|l|}{ Moderately active } \\
\hline MJ & $5 \cdot 9-9 \cdot 2$ & $5 \cdot 9-8 \cdot 4$ & $10 \cdot 0-11 \cdot 7$ & $8 \cdot 4$ & $10 \cdot 0-11 \cdot 7$ & $8 \cdot 4-9 \cdot 2$ & $9 \cdot 2-10 \cdot 0$ & $7 \cdot 5$ \\
\hline kcal & $1400-2200$ & 1400-2000 & $2400-2800$ & 2000 & $2400-2800$ & $2000-2200$ & $2200-2400$ & 1800 \\
\hline \multicolumn{9}{|l|}{ Sedentary } \\
\hline MJ & & & $9 \cdot 2$ & $7 \cdot 5$ & $9 \cdot 2$ & $7 \cdot 5$ & $8 \cdot 4$ & $6 \cdot 7$ \\
\hline kcal & & & 2200 & 1800 & 2200 & 1800 & 2000 & 1600 \\
\hline Total fat $(\% \mathrm{E})^{\star}$ & \multicolumn{2}{|c|}{25 to 35} & \multicolumn{2}{|c|}{20 to 35} & \multicolumn{2}{|c|}{20 to 35} & \multicolumn{2}{|c|}{20 to 35} \\
\hline $\begin{array}{l}\text { Saturated fat } \\
\text { (\%E) }\end{array}$ & \multicolumn{2}{|c|}{$\begin{array}{c}\text { 'As low as possible' } \\
(\leq 10)\end{array}$} & \multicolumn{2}{|c|}{$\begin{array}{c}\text { 'As low as possible' } \\
(\leq 10)\end{array}$} & \multicolumn{2}{|c|}{$\begin{array}{c}\text { 'As low as possible' } \\
(\leq 10)\end{array}$} & \multicolumn{2}{|c|}{$\begin{array}{c}\text { 'As low as possible' } \\
(\leq 10)\end{array}$} \\
\hline Protein $(\% \mathrm{E})^{*}$ & \multicolumn{2}{|c|}{10 to 30} & \multicolumn{2}{|c|}{10 to 35} & \multicolumn{2}{|c|}{10 to 35} & \multicolumn{2}{|c|}{10 to 35} \\
\hline Carbohydrate $(\% \mathrm{E})^{\star}$ & \multicolumn{2}{|c|}{45 to 65} & \multicolumn{2}{|c|}{45 to 65} & \multicolumn{2}{|c|}{45 to 65} & \multicolumn{2}{|c|}{45 to 65} \\
\hline Fibre $(\mathrm{g})+\ddagger$ & \multirow{2}{*}{\multicolumn{2}{|c|}{$\begin{array}{l}\text { Age }+5 g \neq \\
8 \text { to } 11\end{array}$}} & \multirow{2}{*}{\multicolumn{2}{|c|}{$\begin{array}{l}\text { Age }+5 g \neq \\
8 \text { to } 11\end{array}$}} & \multicolumn{2}{|c|}{$25 \mathrm{gt}$} & \multicolumn{2}{|c|}{$25 \mathrm{gt}$} \\
\hline $\mathrm{Fe}(\mathrm{mg}) \S$ & & & & & 7 & $10(6)$ & 7 & 6 \\
\hline $\mathrm{Ca}(\mathrm{mg}) \|$ & \multicolumn{2}{|c|}{800 to 1300} & \multicolumn{2}{|c|}{1300} & \multicolumn{2}{|c|}{1000} & \multicolumn{2}{|c|}{1200} \\
\hline Vitamin D $(\mu \mathrm{g}) \|$ & \multicolumn{2}{|c|}{5} & \multicolumn{2}{|c|}{5} & \multicolumn{2}{|c|}{5} & 5 & \\
\hline
\end{tabular}

$\% \mathrm{E}$, percentage of energy intake.

*Estimated energy requirements (in kcal) for each gender and age group for 'moderate' physical activity based on the Institute of Medicine (IOM) recommendations for reference-sized individuals. 'Reference size' is based on median height and weight for age up to 18 years; and, for adults, median height and weight for that height to give a BMI of $21.5 \mathrm{~kg} / \mathrm{m}^{2}$ for females and $22.5 \mathrm{~kg} / \mathrm{m}^{2}$ for males. 'Moderately active' is described as a lifestyle that includes physical activity equivalent to walking about 1.5 to 3 miles/d at 3-4 miles/h, in addition to the light physical activity associated with typical day-to day life. 'Sedentary' means a lifestyle that includes only the light physical activity associated with typical day-to-day life ${ }^{(31)}$. It was deemed inappropriate to include energy goals for a 'sedentary' lifestyle for children aged $5-13$ years.

tDietary fibre intake goals for adults as recommended by the Irish Heart Foundation ${ }^{(15)}$.

‡Dietary fibre goals for children aged 5-18 years as recommended by the American Health Foundation ${ }^{(32)}$.

§stimated Average Requirements (EAR) for Fe intakes for all adults and teenagers aged between 14 and 18 years. Nordic Nutrition Recommendations have no EAR for children aged 2-13 years. Instead the following Recommended Intakes (RI) were used: Rl of $8 \mathrm{mg}$ for age $2-5 \mathrm{years}$; RI of $9 \mathrm{mg}$ for age $6-9$ years; $\mathrm{RI}$ of $11 \mathrm{mg}$ for age $10-13$ years. Postmenopausal women have an EAR of $6 \mathrm{mg}^{(33)}$.

$\|$ Adequate Intakes $(\mathrm{Al})$ for $\mathrm{Ca}$ and vitamin $\mathrm{D}^{(34)}$.

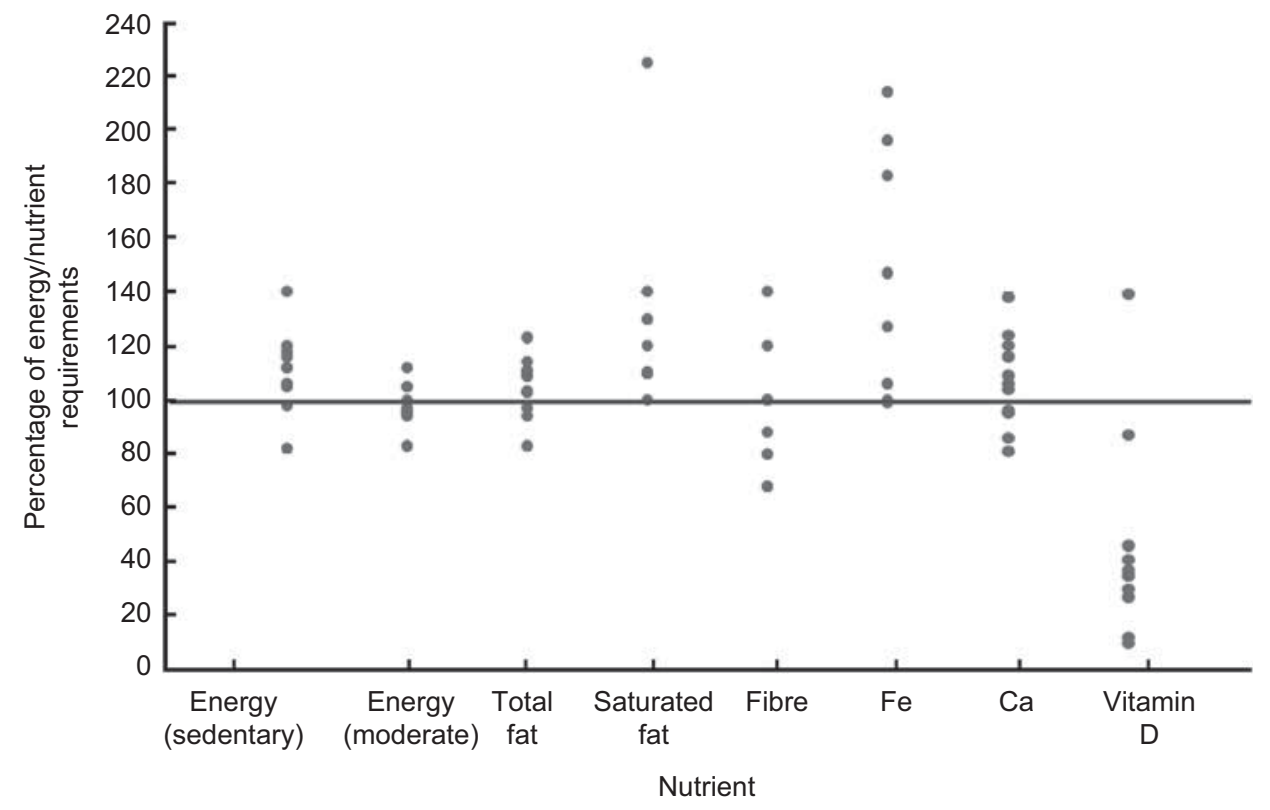

Fig. 1 The range of energy and nutrient intakes provided by the food patterns for eleven hypothetical subjects compared with their recommended intake goals for these nutrients (represented by the solid line at $100 \%$ )

for adults and teenagers. This trend was similar for all subgroups, although more men than women preferred larger portions $(P<0 \cdot 001)$ and more of those aged over
50 years than under 50 years favoured smaller portions $(P<0 \cdot 01)$. There was no difference in responses according to supermarket location. Almost $60 \%$ of respondents 
Table 2 Evaluation of Ireland's Food Guide to Healthy Eating (1992-2007) using 4 d food intake patterns developed for eleven hypothetical subjects representing the four age and gender groups*: findings on average daily nutritional quality of the diets and the appropriateness of food-based advice

(a) Average daily nutritional quality of $4 \mathrm{~d}$ food intake patterns generated for eleven individuals

Goal

Proportion (\%) and number of $4 \mathrm{~d}$ food patterns achieving nutritional goals

Energy

Total fat $(20-35 \% \mathrm{E}$ for adults, $25-35 \% \mathrm{E}$ for children)

Saturated fat ('as low as possible'; $\leq 10 \% \mathrm{E}$ )

$90 \%(n 10)$ exceeded requirements for 'sedentary' physical activity levelst $36 \%(n 4)$ exceeded requirements for 'moderate' physical activity levelst $73 \%(n 8)$ exceeded $35 \% \mathrm{E}$

$90 \%(n 10)$ exceeded $10 \% \mathrm{E}$ (average intakes were $11.3 \% \mathrm{E}, 11.5 \% \mathrm{E}$ and

$16.0 \% \mathrm{E}$ for adult, teenage and children's food patterns respectively)

Fibre (g)

$83 \%$ (5 out of 6 ) of adult food patterns had intakes $<25 \mathrm{~g} / \mathrm{d} ; 20 \%$ ( 1 out of 5 )

of children's food patterns did not meet goal of 'age $+5 \mathrm{~g}$ per day'

$\mathrm{Fe}(\mathrm{mg})$

$\mathrm{Ca}(\mathrm{mg})$

Vitamin D $(\mu \mathrm{g})$

$100 \%(n 11)$ met EAR $\ddagger$ and $73 \%(n 8)$ met RI

$82 \%(n 9)$ met Al§ (the two patterns for 9-10-year-olds did not meet Al)

(b) Appropriateness of food-based advice

$90 \%(n 10)$ did not reach All

Areas of significance Description of food advice issue

Food portions in Bread, Cereal and Potato food group

Portions yield wide range of energy (314-1046 kJ (75-250 kcal)) yet advice indicates portions provide equivalent energy $\uparrow$

Portion size descriptions:

(i) Specific in some areas, ambiguous in others

Specific: $28 \mathrm{~g}$ cheese Ambiguous: 1 bowl cereal

(ii) Untypical of eating habits in Ireland $56 \mathrm{~g}$ meat

Placement of foods in food groups

e.g. $56 \mathrm{~g}$ of meat can be eaten twice per day rather than a smaller serving at a light meal and a larger serving at a main meal

(i) Cheese present in both Dairy group and Meat and Alternatives group

(ii) Pulses present in Fruit and Vegetable group, but not in Meat and Alternatives group

Fat spreads, oils and 'other foods'

Fat spreads (e.g. margarines) and oils represented in the same food group as 'other' foods such as crisps, biscuits, cakes, chocolate confectionery, sugar, preserves and sweet drinks, leading to ambiguous advice on types and amount of fat spreads and oils to use

$\% \mathrm{E}$, percentage of energy intake; EAR, Estimated Average Requirement.

*The approach used was to 'translate' the advice on the food guide into $4 \mathrm{~d}$ diet patterns for eleven hypothetical individuals of differing age and sex: two males and one female aged 5-13 years; one male and one female aged 14-18 years; two males and two females aged 19-50 years; and one male and one female aged $51+$ years. In accordance with the advice in the food guide, a mixture of full-fat and reduced-fat spreads and milks were included and 6 to 12 servings from the Bread, Cereal and Potato group were chosen for each individual.

tEstimated energy requirements (in kcal) for each gender and age group for 'moderate' physical activity based on the Institute of Medicine (IOM) recommendations for reference-sized individuals ${ }^{(31)}$. 'Reference size' is based on median height and weight for age up to 18 years; and, for adults, median height and weight for that height to give a BMI of $21.5 \mathrm{~kg} / \mathrm{m}^{2}$ for adult females and $22.5 \mathrm{~kg} / \mathrm{m}^{2}$ for adult males. 'Moderately active' is described as a lifestyle that includes physical activity equivalent to walking about 1.5 to 3 miles/d at 3-4 miles/h, in addition to the light physical activity associated with typical day-to day life. 'Sedentary' means a lifestyle that includes only the light physical activity associated with typical day-to-day life.

¥Evaluation found the food intake patterns developed for the 9-year-old girl, teenage girl and adult woman all failed to provide the goals set for Fe (Recommended Intake (RI) set by the Nordic Nutrition Recommendations) ${ }^{(33)}$.

$\S$ The food intake patterns developed for the teenage girl and adult man over 51 years of age provided $95 \%$ and $96 \%$ respectively of the Adequate Intake (Al) for $\mathrm{Ca}$, which were considered to reach the goals set ${ }^{(34)}$.

$\|$ The food pattern developed for the 16-year-old boy provided an intake of $6 \cdot 75 \mu \mathrm{g}$ vitamin D/d, however, this food intake pattern was exceptional in that it included oily fish twice in $4 \mathrm{~d}$.

-Some publications of the Irish food guide on healthy eating included scones as suitable snack options in sample menus - scones have an average energy content of $1046 \mathrm{~kJ}$.

reported that they would like to change the portion sizes of some of the foods they chose as being closest to their overall idea of 'average'. Larger portions were favoured for high-fibre breakfast cereals ( $5 \%, n$ 51), soda bread $(10 \%, n 102)$, batch bread $(9 \%, n 91)$, rice $(7 \%, n 73)$ and pasta (11\%, $n$ 114); while smaller portions were preferred for mashed potato $(2 \%, n$ 18). However, 62\% ( $n$ 624) favoured the smaller portions for children aged 5-9 years.

From a subsample of 485 shoppers, $73 \%$ ( $n$ 354) preferred the use of a cup compared with $23 \%$ ( $n$ 112) of shoppers who preferred the use of dessertspoon as descriptors. From the 1011 shoppers, 73\% ( $n$ 735) preferred 'palm of hand' as a descriptor for meat portions rather than 'deck of cards'.

\section{Discussion}

In the present evaluation, the food patterns based on Ireland's national food guide were generally found to provide excessive intakes of energy, total fat and saturated fat for most age and gender groups examined, while providing inadequate fibre intakes for adults. More significantly, the advice in Ireland's current food guide delivers only a small proportion of the vitamin D requirements of nearly all age and gender groups examined. Energy provided by the portion sizes of foods in the Bread, Cereal and Potato group were found to vary widely, yet the advice suggested these foods were equivalent in terms of energy. Dietitians/ nutritionists and consumers surveyed found enlarged 
Table 3 Practicality of food guidance for healthy eating: summary of feedback from consultation with dietitians/nutritionists

\begin{tabular}{|c|c|}
\hline Key issues arising & Summary of feedback \\
\hline $\begin{array}{l}\text { Smaller portions of bread, cereal, } \\
\text { potato } v \text {. larger portions }\end{array}$ & $\begin{array}{l}\text { Consensus was reached to support the use of larger portion sizes as these were } \\
\text { considered to be 'more realistic' }\end{array}$ \\
\hline Descriptors used for portion sizes & $\begin{array}{l}\text { Opinion was divided on the suitability of descriptors considered. This included using } \\
\text { the 'palm of hand' or 'deck of cards' for meat/chicken/fish portions; and the use of } \\
\text { actual food weights or household measures (e.g. dessertspoons, cups, etc.) }\end{array}$ \\
\hline Position of foods in food groups & $\begin{array}{l}\text { Due to its high saturated fat content cheese should be confined to the Milk, Yoghurt } \\
\text { and Cheese group rather than be also positioned in the Meat and Alternatives } \\
\text { group. However the cheese consumed as a 'milk, yoghurt and cheese group' may } \\
\text { also count as a 'meat and alternatives group' light meal option (rather than taking } \\
\text { a double portion of cheese). By contrast, pulses, a high-fibre and low-fat food, } \\
\text { should be included in both the Meat and Alternatives group and the Fruit and } \\
\text { Vegetables group as double portions of pulses help achieve nutrient goals }\end{array}$ \\
\hline $\begin{array}{l}\text { Separation of fat spreads and oils into } \\
\text { a separate food group (providing } \\
\text { unsaturated fats) }\end{array}$ & $\begin{array}{l}\text { Consensus reached to separate fats (spreads) and oils into a new food group } \\
\text { instead of including these foods within the Other Foods group which contain foods } \\
\text { high in fat, salt and/or sugar, e.g. crisps, cakes, chocolate, confectionery, biscuits, } \\
\text { sweet drinks, etc. }\end{array}$ \\
\hline $\begin{array}{l}\text { Whether sugar and preserves can be } \\
\text { used 'sparingly' to increase palatability } \\
\text { of low-fat, high-fibre foods }\end{array}$ & $\begin{array}{l}\text { Cautious agreement that use of sugar and preserves can be advised sparingly in the } \\
\text { context of increasing acceptability of low-fat, high-fibre foods; e.g. a little sugar } \\
\text { with porridge and preserves used to replace fat spread on bread }\end{array}$ \\
\hline
\end{tabular}

portions of these foods more meaningful than the smaller portions traditionally used in the food guide. Advice on the appropriate amounts and types (unsaturated $v$. saturated) of fats and oils was found to be ambiguous. The most appropriate placement of foods such as cheese and pulses in relevant food groups also requires reconsideration.

The food patterns based on the food guide provided excessive energy and total fat intakes compared with established goals. These findings are particularly relevant given the high rates and rising prevalence of obesity in Ireland that currently affects all age groups ${ }^{(8-10)}$. High total fat intakes contribute to the energy density of the diet and are associated with an increased risk of obesity ${ }^{(38)}$. Energydense diets have been found to lead to overconsumption of energy, termed 'passive overconsumption'(39-41). According to the Irish National Food Consumption Surveys, the mean daily total fat intakes of teenagers and adults $^{(42)}$ are comparable to the average levels provided by food patterns based on the food guide (36\% v. 36\%, respectively). Ireland's food pyramid guide to healthy eating was not originally designed to provide guidance on energy intake. Revisions to address this will need to consider variations in energy requirements according to age, gender and physical activity levels.

CVD is a leading cause of mortality accounting for more than one-third (36\%) of all deaths in Ireland ${ }^{(43)}$; thus, public health measures to reduce the prevalence of CVD remain a priority. Due to the positive linear trend between saturated fat intake and LDL cholesterol, there is a consensus among international nutrition panels that saturated fat intakes should be kept as low as possible while consuming a nutritionally adequate diet ${ }^{(31,44)}$. In the present evaluation, all but one of the average daily intakes based on Ireland's food pyramid advice exceeded the previous international recommendations for saturated fat $\left(\leq 10 \%\right.$ energy from saturated fat ${ }^{(45-47)}$. The National
Food Consumption Surveys have found that only $6 \%$ of children (5-12 years), $11 \%$ of teenagers (13-17 years) and $21 \%$ of adults (18-64 years) reached this $\leq 10 \%$ saturated fat goal $^{(42)}$, which is less stringent than the current recommendation to keep saturated fat intakes 'as low as possible, (31). Overall, average intakes of energy from saturated fat assessed in these surveys was $14-15 \%{ }^{(42)}$, which is equivalent to the level provided by the food guide food patterns. In addition to the need to reduce total fat, revision of Ireland's food guide needs to prioritize reduction of saturated fat.

Overall, the evaluated food patterns did not provide sufficient vitamin D to meet the AI. These findings are in line with many Irish studies showing inadequate dietary intakes $^{(28-30)}$ and poor vitamin D status ${ }^{(48,49)}$. Rickets has reemerged in Ireland in recent years, prompting recommendations that all infants be supplemented with vitamin D $\left(5 \mu \mathrm{g}\right.$ (200 IU) daily) ${ }^{(50)}$. Poor vitamin D status has serious implications for the long-term risk of osteoporosis, which is currently estimated to affect one in three women and one in five men in Ireland ${ }^{(51)}$. Furthermore, poor vitamin D status may impact negatively on other chronic diseases prevalent in Ireland such as cancer ${ }^{(22,23)}$ and $\mathrm{CVD}^{(23,25)}$. Specific advice on how to obtain adequate vitamin $\mathrm{D}$ intakes is urgently needed in the revision of Ireland's food guide.

The food guide was shown to provide inadequate fibre intakes for adults, particularly those with lower energy requirements. Dietary fibre plays an important role in the prevention of gastrointestinal disease, particularly colon cancer $^{(52)}$. Data from the National Cancer Registry of Ireland shows that colorectal cancer was the third most common form of cancer in Ireland, accounting for $12 \%$ of cancers in women and $15 \%$ in men in 2005-2007, with colorectal cancer being the second commonest cause of cancer death ${ }^{(53)}$. Increasing fibre intakes remains a priority in the revision of Ireland's food guide. 
Portion sizes of foods from the Bread, Cereal and Potato group, advised by the food guide, were generally small and many foods consisted of half units (e.g. half a bread roll). With a few exceptions, the larger portion sizes facilitate the use of whole units of food (e.g. a whole bread roll). Furthermore, where these larger portions include more than one unit (e.g. 1 portion $=2$ slices of bread), this also reflects the way people eat, e.g. one sandwich. These findings are in agreement with the portion sizes used in the most recent Australian food guide ${ }^{(37)}$. While it is recognized that the sample of shoppers surveyed was not a nationally representative sample, their input provided a valuable indicator of what end-users would find most meaningful. Such input is a vital part of the development of food-based dietary guidelines ${ }^{(44)}$. Since larger portions are more meaningful to consumers, using them will enable more effective communication on energy intake. The Bread, Cereal and Potato food group represents the best source of energy, in that appropriate foods are low in fat and high in fibre. Therefore, revision of this food group is pivotal to tackling the rising prevalence of obesity ${ }^{(7-9)}$ and other inadequacies identified (e.g. fat, fibre).

Portion sizes of all foods consumed within and outside the home have increased and this has been identified as a key environmental factor contributing to the development of obesity ${ }^{(54,55)}$. Portion size descriptors that are easily understood by the population are needed for effective communication on appropriate food portion size. The finding that household measures (e.g. $200 \mathrm{ml}$ cup) and other descriptors (e.g. a portion of meat the size of the "palm of hand') were preferred, was in agreement with research conducted in Scotland indicating that weights of foods were perceived to be too prescriptive ${ }^{(5)}$.

Communication of healthy eating messages to reduce fat and increase fibre intakes could be enhanced by reconsidering the inclusion of key food sources of these nutrients in particular food groups. For example, the inclusion of fat spreads and oils in the same category of foods that simply need to be limited (e.g. cakes, confectionery, etc.) inhibits the specific advice required to guide on appropriate type and amounts of fat. Support for limiting cheese to one food group only is evident from recent revisions of other national food guides, which also advise that dairy servings be provided mostly by lower-fat $\mathrm{Ca}$ sources such as low-fat yoghurts and milks ${ }^{(11,12,37)}$. However, the double placement of highfibre, low-fat pulses in food groups is appropriate, e.g. Meat and Alternatives in addition to the Fruit and Vegetables group.

The energy and nutrient goals are well established in both Europe $^{(44)}$ and North America ${ }^{(31)}$. Fibre intake goals in children are uncertain ${ }^{(57)}$. In the present evaluation, the fibre goal for children over the age of 2 years ('age $+5 \mathrm{~g}$ ' of dietary fibre per day) recommended by the American Health Foundation ${ }^{(32)}$ was used in preference to the more recent IOM goal (14g fibre/1000 kcal (4184kJ) per d) 
which is a simple extrapolation from adult data on fibre requirements ${ }^{(31)}$.

In the absence of micronutrient recommendations from the European Food Safety Authority, the North American $\mathrm{AI}$ for $\mathrm{Ca}$ and vitamin D were used ${ }^{(34)}$. The higher AI for Ca applies from the age of 9 years. Due to the lower energy intakes of this age group, this goal can be difficult to achieve. The Irish goals for Fe intake take account of the mix of haem and non-haem $\mathrm{Fe}$ in the Irish diet and have traditionally been set to cover the requirements of most of the population apart from those women who have exceptionally high requirements due to high menstrual losses ${ }^{(58)}$. These goals for Fe intake have tended to be lower than those set in North America and more in line with those recently updated in the Nordic Nutrition Recommendations $^{(33)}$, which were used in the present evaluation. Assessment of other micronutrients and specific fatty acids provided by food patterns based on Ireland's national food guide were beyond the scope of the present evaluation, which focused on micronutrients identified as problematic in recent national surveys ${ }^{(17-20,27-29)}$.

Given evolving food habits, prevalence of nutritionrelated public health issues and population demographics, there is a need to regularly review and update national food guides on healthy eating. The present evaluation found revision of Ireland's food guide for healthy eating requires specific guidance on energy and vitamin D intakes; and comprehensive advice on how to reduce fat and saturated fat and increase fibre intakes. In addition, advice should use portion descriptors favoured by consumers and enlarged portion sizes for breads, cereals and potatoes that are equivalent in terms of energy. All of these issues are addressed in Phase 2 of the revision of food-based dietary guidelines for Ireland ${ }^{(59)}$.

\section{Acknowledgements}

The work reported in this submitted manuscript was funded by the Food Safety Authority of Ireland (FSAI). There are no conflicts of interest. The contribution of each author to the submitted manuscript is as follows. M.A.T.F.: research design, overall supervision and co-author of the manuscript; C.M.O'B.: main researcher on all aspects of this work, supervision of research assistants, co-author of the manuscript; G.F.: research assistant on assessment of portion sizes for healthy eating advice and contributor to manuscript write-up; C.A.F.: research assistant on development and analysis of the food intake patterns and contributor to the manuscript; M.G.: research assistant on development of nutrient goals for healthy eating in Ireland and development and analysis of food intake patterns; S.J.B.: research assistant on assessment of portion sizes for healthy eating advice and contributor to the manuscript. The advice and input of Members of the Steering Committee on Revision of the Food Based Dietary Guidelines for Ireland, FSAI are gratefully acknowledged. Thanks are also due to the administrative staff at the FSAI who helped to format and prepare the manuscript: Aileen Ward, Alice Kenny, Nicola Canning, Niamh Devaney and Marianne McFeely.

\section{References}

1. Institute of Medicine (2006) Dietary Reference Intakes: The Essential Guide to Nutrient Requirements. Washington, DC: The National Academies Press.

2. Welsh S, Davis C \& Shaw A (1992) Development of the Food Guide Pyramid. Nutr Today 27, issue 6, 12-23.

3. National Research Council, Food and Nutrition Board (1989) Recommended Dietary Allowances, 10th ed. Washington, DC: National Academy Press.

4. Nutrition and Health Foundation (2011) Food Pyramid Poster. http://www.nutritionandhealth.ie/Sectors/nhf/nhf.nsf/ vPages/Eat_Smart food-pyramid?OpenDocument (accessed May 2011)

5. World Health Organization (2000) Obesity: Preventing and Managing the Global Epidemic WHO Technical Report Series no. 894. Geneva: WHO.

6. Popkin BM \& Doak C (1998) The obesity epidemic is a worldwide phenomenon. Nutr Rev 56, 106-114.

7. Hill JO (2009) Can a small change approach help address the obesity epidemic? Am J Clin Nutr 89, 477-484.

8. McCarthy SN, Harrington KE, Kiely M et al. (2001) Analyses of the anthropometric data from the North/South Ireland Food Consumption survey. Public Health Nutr 4, 1099-1106.

9. Whelton H, Harrington J, Crowley E et al. (2007) Prevalence of overweight and obesity on the island of Ireland: results from the North South survey of children's height, weight and body mass index 2002. BMC Public Health 7, 187.

10. O'Neill JL, McCarthy SN, Burke SJ et al. (2007) Prevalence of overweight and obesity in Irish schoolchildren, using four different definitions. Eur J Clin Nutr 61, 743-751.

11. Health Canada (2007) Eating well with Canada's Food Guide. http://www.healthcanada.gc.ca/foodguide (accessed September 2009).

12. US Department of Health and Human Services \& US Department of Agriculture (2005) Dietary Guidelines for Americans. Washington, DC: USDA.

13. US Department of Agriculture (2010) Report of the Dietary Guidelines Advisory Committee on the Dietary Guidelines for Americans. Washington, DC: USDA; available at http:// www.cnpp.usda.gov/DGAs2010-DGACReport.htm

14. Department of Health and Children (2005) Obesity - The Policy Challenges. The Report of the National Taskforce on Obesity. Dublin: Stationery Office.

15. Irish Heart Foundation (2007) Nutrition Guidelines for Heart Health with Policy Recommendations. Dublin: The Irish Heart Foundation Nutrition Council.

16. Harrington KE, McGowan MJ, Kiely M et al. (2001) Macronutrient intakes and food sources in Irish adults: findings of the North/South Ireland Food Consumption Survey. Public Health Nutr 4, 1051-1060.

17. Galvin MA, Kiely M, Harrington KE et al. (2001) The North/ South Ireland Food Consumption Survey: the dietary fibre intake of Irish adults. Public Health Nutr 4, 1061-1068.

18. Hayes E, Walton E, Hannon M et al. (2009) Micronutrient intakes in Irish teenagers (13-17 years). Proc Nut Soc 67, OCE7, E275.

19. Hannon EM, Kiely M, Harrington KE et al. (2001) The North South Ireland Food Consumption Survey: mineral intakes in 18-64 year old adults. Public Health Nutr 4, 1081-1088.

20. Ryan YM (1997) Meat avoidance and body weight concerns: nutritional implications for teenage girls. Proc Nutr Soc 56, 519-524. 
21. Von Essen MR, Kongsbak M, Schjerling P et al. (2010) Vitamin D controls $\mathrm{T}$ cell antigen receptor signalling and activation of human T cells. Nat Immunol 11, 344-349.

22. Mohr SB (2009) A brief history of vitamin D and cancer prevention. Ann Epidemiol 19, 79-83.

23. Holick MF (2004) Vitamin D: importance in the prevention of cancers, type I diabetes, heart disease and osteoporosis. Am J Clin Nutr 79, 362-371.

24. Harris S (2002) Can vitamin D supplementation in infancy prevent type I diabetes? Nutr Rev 60, 118-121.

25. Judd SE \& Tangprichen V (2009) Vitamin D deficiency and risk for cardiovascular disease. Ann J Med Sci 338, 40-44.

26. Holick MF (2008) Vitamin D - a D-lightful health perspective. Nutr Rev 66, Suppl. 2, S182-S194.

27. Ovesen L, Andersen R \& Jakobsen J (2003) Geographical differences in vitamin D status with particular reference to European countries. Proc Nutr Soc 62, 813-821.

28. Kiely M, Hannon EM, Walton J et al. (2005) Vitamin D intakes in Irish 5-12 year old schoolchildren. Proc Nutr Soc 64, 38A.

29. Hill TR, O'Brien MM, Cashman KD et al. (2004) Vitamin D intakes in 18-64 year old Irish adults. Eur J Clin Nutr 58, 1509-1517.

30. O'Brien MM, Kiely M, Harrington KE et al. (2001) The North/South Food Consumption Survey: vitamin intakes in 18-64 year old adults. Public Health Nutr 4, 1069-1079.

31. Institute of Medicine (2002) Dietary Reference Intakes. Macronutrients Report. Washington, DC: National Academies Press.

32. Williams CL, Bollela N \& Wynder EL (1995) A new recommendation for dietary fiber in childhood. Pediatrics 96, 985-988.

33. Norden (2004) Nordic Nutrition Recommendations: Integrating Nutrition and Physical Activity, 4th ed. Copenhagen: Nordic Council of Ministers.

34. Institute of Medicine (1997) Adequate Intakes (AI's) for Calcium and Vitamin D: Dietary Reference Intakes for Calcium, Phosphorus, Magnesium, Vitamin D and Fluoride. Washington, DC: National Academies Press.

35. Food Standards Agency (2002) Food Portion Sizes. London: HMSO.

36. McCance RA \& Widdowson EM (2002) The Composition of Foods, 6th ed. Cambridge: Royal Society of Chemistry \& Food Standards Agency.

37. National Health and Medical Research Council (2003) Food for Health. Dietary Guidelines for Australians. A Guide to Healthy Eating. Canberra: Australian Government Department of Health and Aging; available at http://www.health. gov.au/internet/main/publishing.nsf/Content/health-pubhlthstrateg-food-guide-index.htm

38. Bray GA, Paeratakul S \& Popkin MB (2004) Dietary fat and obesity: a review of animal, clinical and epidemiological studies. Physiol Behav 83, 549-555.

39. Poppitt SD \& Prentice AM (1996) Energy density and its role in the control of food intake: evidence from metabolic and community studies. Appetite 26, 153-174.

40. Viskaal-van Dongen M, de Graaf C, Siebelink E et al. (2009) Hidden fat facilitates passive overconsumption. J Nutr 139, 394-399.

41. Westerterp KR (2006) Perception, passive overfeeding and energy metabolism. Physiol Behav 89, 62-65.

42. Joyce T, Wallace AJ, McCarthy S et al. (2009) Intakes of total fat, saturated, monounsaturated and polyunsaturated fatty acids in Irish children, teenagers and adults. Public Health Nutr 12, 156-165.
43. Central Statistics Office (2006) Vital Statistics 4th Quarter and Yearly Summary 2005. Dublin: Central Statistics Office; available at http://www.cso.ie/newsevents/press release_vitalstatisticsq4and year2005.htm

44. European Food Safety Authority, Panel on Dietetic Products, Nutrition and Allergies (2010) Scientific opinion on establishing Food-Based Dietary Guidelines. EFSA J 8, 1460.

45. Krauss RM, Deckelbaum RJ, Ernst N et al. (1996) Dietary Guidelines for Healthy American Adults: a statement for health professionals from the Nutrition Committee, American Heart Association. Circulation 94, 1795-1800.

46. Department of Health (1991) Dietary Reference Values for Food Energy and Nutrients for the United Kingdom Committee on Medical Aspects of Food Policy Report on Health and Social Subjects no. 41. London: HMSO.

47. Food and Agriculture Organization of the United Nations/ World Health Organization (2008) Joint Expert Consultation on Fats and Fatty Acids in Human Nutrition: Interim Summary of Conclusions and Dietary Recommendations on Total Fat and Fatty Acids. Geneva: WHO; available at http://www.who.int/nutrition/topics/FFA_summary_rec_ conclusion.pdf

48. McCarthy D, Collins A, O'Brien M et al. (2006) Vitamin D intake and status in Irish elderly women and adolescent girls. Irish J Med Sci 175, 14-20.

49. Hill TR, Flynn A, Kiely M et al. (2006) Prevalence of suboptimal vitamin D status in young, adult and elderly Irish subjects. Irish Med J 99, 48-49.

50. Food Safety Authority of Ireland (2007) Recommendations for a National Policy on Vitamin D Supplementation for Infants in Ireland. Dublin: FSAI.

51. Health Service Executive, Department of Health and Children \& National Council on Aging and Older People (2008) Strategy to prevent falls and fractures in Ireland's Ageing Population. http://www.hse.ie/eng/services/news centre/2008_Archive/Aug_2008/Preventing_Falls_and_Fractures. html (accessed May 2011).

52. Gonzalez CA \& Riboli E (2010) Diet and cancer prevention: contributions from the European Prospective Investigation into Cancer and Nutrition (EPIC) Study. Eur J Cancer $\mathbf{4 6}$ $2555-2562$.

53. National Cancer Registry of Ireland (2009) Incidence, mortality, treatment and survival. http://www.ncri.ie/ 20090424.shtml (accessed September 2010).

54. Ello-Martin JA, Ledwike JH \& Rolls B (2005) The influence of portion size and energy density on energy intake: implications for weight management. Am J Clin Nutr $\mathbf{8 2}$ Suppl. 1, 236S-241S.

55. Kelly MT, Wallace JM, Robson PJ et al. (2009) Increased portion size leads to sustained increase in energy intake over 4 days in normal-weight and overweight men and women. BrJ Nutr 102, 470-477.

56. Anderson AS, Barton K, Craigie A et al. (2008) Exploration of Adult Food Portion Size Tools. Edinburgh: NHS Health Scotland; available at http://www.healthscotland.com/ uploads/documents/6505-RE018FinalReport0708.pdf

57. Slavin JL (2008) The position of the American Dietetic Association: health implications of dietary fiber. J Am Diet Assoc 108, 1716-1731.

58. Food Safety Authority of Ireland (1999) Recommended Dietary Allowances for Ireland. Dublin: FSAI.

59. Flynn MAT, O'Brien CM, Ross V et al. (2011) Revision of food-based dietary guidelines for Ireland, Phase 2: recommendations for healthy eating and affordability. Public Health Nutr (Epublication ahead of print version). 